\title{
Research Paper: Effect of Isometric Exercises on Ability and Balance of Patients With Multiple Sclerosis
}

\author{
Nasrin Zahmatkeshan ${ }^{1}$, Hamdollah Delaviz ${ }^{2 *}$ \\ 1. Department of Operating Room, School of Paramedicine, Yasuj University of Medical Sciences, Yasuj Iran. \\ 2. Cellular and Molecular Research Center, School of Medicine, Yasuj University of Medical Sciences, Yasuj, Iran.
}

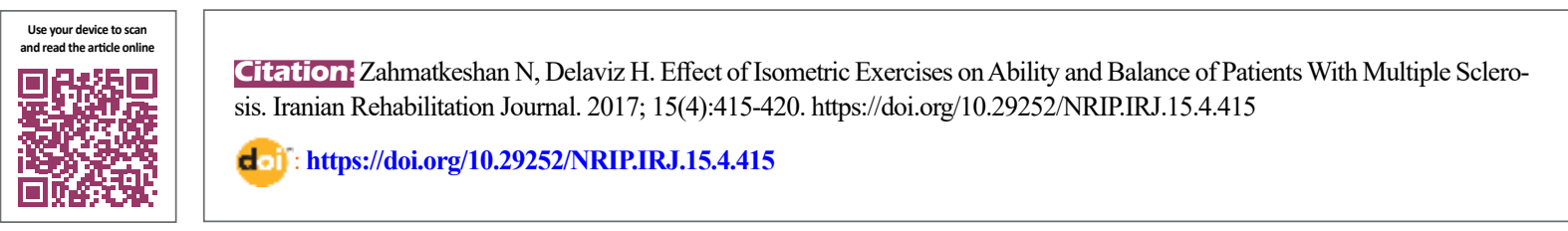

Article info:

Received: 06 Jul. 2017

Accepted: 25 Oct. 2017

\section{Keywords:}

Multiple Sclerosis, Isometric exercise, Patients, Rehabilitation

\section{ABSTRACT}

Objectives: Multiple Sclerosis (MS) is a chronic and disabling disease of the nervous system. This study was conducted to determine the effect of isometric exercises on balance and ability in the patients with MS.

Methods: Sixty MS patients participated in this randomized controlled trial study and patients were randomly assigned into treatment and control groups. Treatment group participated in an isometric exercise program for 8 weeks and the control group followed routine treatment program. Expanded Disability Status Scale (EDSS) and Berg Balance Scale (BBS) were used to measure disability and balance status, respectively, on days 1,28 , and 56 post treatment.

Results: No significant difference was observed in the mean scores of EDSS and BSS between the control and treatment groups on day 1 post treatment. Mean scores of EDSS and BSS significantly decreased and increased, respectively, in the treatment group compared with the control group on day 56 post treatment $(\mathrm{P}<0.01)$. Repeated measures test in the treatment group showed there was a statistically significant difference between the mean scores of EDSS and BSS on day 1 compared with that on days 28 and 56 post treatment $(\mathrm{P}<0.001)$, while in control group there was no significant difference between the mean scores of EDSS and BSS.

Discussion: Isometric exercise programs improved balance and reduced the severe disability in MS patients and recommended as a complementary treatment program for MS patients.

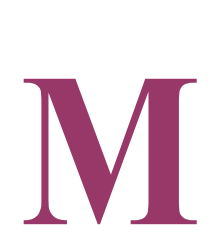

\section{Introduction}

ultiple Sclerosis (MS) is a chronic and disabling disease of the nervous system caused as a result of nerve demyelination [1]. The symptoms of this disease depend on the location of demyelination and extent of the lesion. Like other neurodegenerative diseases, repair in MS with an increase of age is little and slow $[2,3]$. Demyelination in certain areas including optic nerve, brainstem, cerebellum, and white matter of the hemispheres causes different symptoms such as sudden visual disturbances (blurred vision), disability in limb movement, balance disorder, and sensory disorders like numbness and tingling in the limbs [3]. Earlier report indicates that the quality of life for people with MS

\section{* Corresponding Author:}

Hamdollah Delaviz, PhD

Address: Cellular and Molecular Research Center, School of Medicine, Yasuj University of Medical Sciences, Yasuj, Iran.

Tel: +98 (741) 2235146

E-mail:delavizhamdi83@gmail.com 
is negatively affected by disability, fatigue, depression, and stress [3]. Among the general population, MS affects mostly young women and nearly 2.3 million people across the world suffer from this disease [4]. Different symptoms such as abnormal walking, balance disorder, muscle weakness, fatigue, muscle spasms, and sensory disorders have been observed in the people with MS [3, 5]. Previous study on MS patients has shown that more than $50 \%$ of the patients had balance disorder and disability in walking associated with muscular weakness of the upper and lower limbs [6]. Furthermore, disruption in stability, decrease in functional independence, and risk of falling are the main problems of these patients [7].

To date, no definitive treatment method has been introduced for patients with MS. Drug therapies including steroids, cyclosporine, and interferons are used to control symptoms and reduce the demyelination process $[8,9]$. The olfactory mucosa or nerve growth factor and collagen gel have a protective effect on remyelination of damaged nerve in an experimental study [10]. Reflexology and relaxation have been shown to be effective interventions for improving life quality and relieving anxiety of patients with MS [4]. Exercises such as aquatic exercises and aerobic exercises can improve walking, reduce fatigue, and improve life quality in these patients [11]. Notably, resistance exercise has beneficial effects on increasing muscular strength and could improve the daily performance in MS patients [12]. Currently, these exercises are mostly used in the rehabilitation of the patients with paresis, surgical motor problems, lower back and neck pain. One common problem of patients with MS is fatigue and reduced ability for movement and they can not participate in different exercise programs [3]. Isometric exercises are very simple and do not require any special tools. Thus, these exercises can be suggested for different age groups as patients can do them at any time of the day and in every situation [12]. To the best of our knowledge, there is no specific study conducted on the impacts of isometric exercises on MS patients. Therefore, the present research was undertaken to determine whether isometric exercise can improve muscle strength, balance, and ability of patients with MS.

\section{Methods}

Ethical considerations and groups

This study was approved by the biomedical research ethics committee of the Yasuj University of Medical Sciences (Yums.REC.1394.101) and was registered in the Iranian Registry of Clinical Trials (IRCT2017011732000N1). This randomized clinical trial research with a pretest-posttest design involved 60 patients with MS referring to the special diseases center in Yasuj who entered in this study with informed consent during 2015-2016. Patients were eligible to be included in the study only if they were between the ages of 20-45 years, with two-year history of diagnosis to the MS disease, absence of acute disease phase, ability to do physical movements, and no participation in similar studies at the same time. MS patients who suffer from other diseases such as diabetes mellitus, Parkinson's, Alzheimer's, and Huntington's or do not have the appropriate psychological conditions were excluded from this study. After obtaining permission from the Department of Health and Ethics Committee of the Yasuj University of Medical Sciences (Yums.REC.1394.101), the purpose of the study was explained to the participants in the first session. The patients were examined by a physiotherapist to give the scores of disability and balance status for each individual. Then, they were randomly divided equally into control and treatment groups $(\mathrm{n}=30$ patients for each group). Afterwards, isometric exercise techniques were instructed by a physiotherapist to the treatment group in 2 training sessions of 2 hours each.

\section{Intervention}

The exercise intervention was considered for treatment group, and the patient was trained by a physiotherapist. The aim of the exercise program was to moderately increase the duration and strength intensity to improve the balance and ability of the patients. These exercises included knee extension isometric exercise, isometric abdominal exercise, isometric neck exercise, isometric elbow extension, and isometric wrist extension. After the necessary training, the patient performed these exercises 3 times per day for 8 weeks. The duration of each exercise was $30 \mathrm{~s}$ at the start time and $20 \mathrm{~s}$ were added gradually in the subsequent sessions. Gradually, the patient increased the time of exercise to reach a maximum of 4 to $5 \mathrm{~min}$. However, the duration was determined based on the patients' tolerance. Both groups were followed up by telephone coaching call 3 times a week for 8 weeks. The control group received drug therapy care according to the neurologist's prescription. EDSS and BBS were used in order to measure disability and balance status, respectively on days 1,28 , and 56 post treatment for both groups.

\section{Data gathering instruments}

A questionnaire was used for collection of demographic data including age, sex, marital status, job, history, and duration of disease (Table 1). EDSS and BBS were used to measure disability and balance status, respectively, 


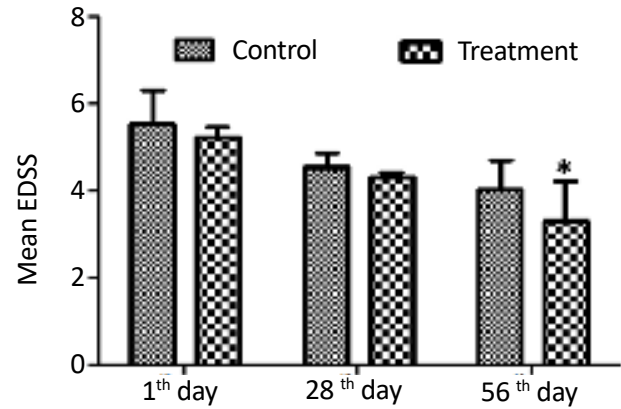

Dranlan iaknablitution Journal

Figure 1. Decrease in Expanded Disability Status Scale (EDSS) score recorded on days 1,28 and 56 post treatment

${ }^{*} \mathrm{P}<0.01$, compared with the control group (Independent $\mathrm{t}$-test)

in patients. EDSS is one of the most common ranking scales used in the measurement of neurological disorders and is a method of quantifying disability in MS $[13,14]$. The BBS is a valid method of quantifying disability to measure the balance among the patients with MS in a clinical setting. This scale has 14 items that measure and score the balance status of patients with various conditions between $0-4$ rating scale, where 0 represents minimum performance and 4 maximum.

\section{Statistical analysis}

For data analysis, independent t-test and repeated measures test were used. All data are expressed as mean \pm SD and a $\mathrm{P}<0.05$ was considered to be statistically significant.

\section{Results}

As shown in Table 1, the mean age of the participants was 36.1 years, $73 \%$ of whom were women, $73.3 \%$ were married, $45 \%$ housewives, and $45 \%$ had MS more than

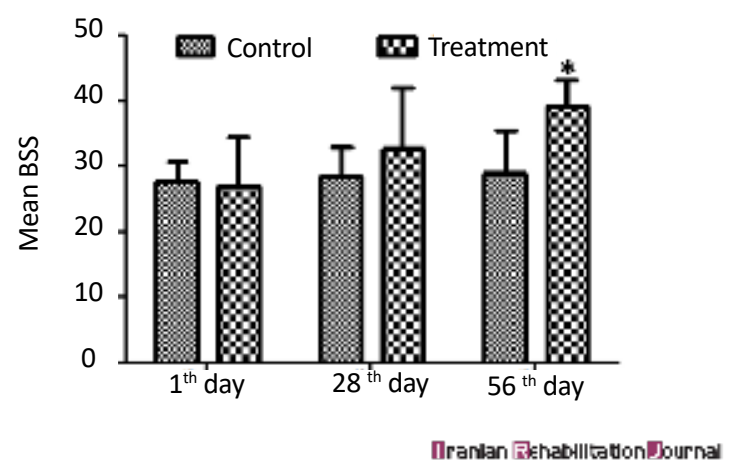

Figure 2. The mean scores of the Berg Balance Scale (BBS) increased in treatment group during treatment

$* \mathrm{P}<0.01$, compared with the control group (Independent $\mathrm{t}$-test)

5 years ago. Independent t-test showed no statistically significant difference in age, sex, education, job, and history of disease between the two groups (Table 1). Independent sample t-test also revealed no significant difference in the mean score of EDSS and BSS between the two groups on day 1 of the study program (Figure 1). On day 1 of the exercise program, the mean scores of EDSS and BSS in the treatment group were 5.24 \pm 0.21 and 27.01 \pm 7.33 , respectively; while independent sample t-test showed no significant difference in the control group (Figure 1, 2). Eight weeks after treatment, the mean scores of EDSS and BSS in the treatment group were $4.01 \pm 0.69$ and $29.03 \pm 6.31$, respectively. The difference was significant compared with the control group $(3.58 \pm 0.74,41.03 \pm 9.02)(\mathrm{P}<0.01)$. Repeated measures test in the treatment group showed that there was a statistically significant difference in the mean scores of EDSS and BSS on day 1 compared with that at the end of 4 and 8 weeks after intervention $(\mathrm{P}<0.001)$. However, these values were not significant in control group at these intervals $(\mathrm{P}=0.177)$ (Figure 3,4$)$.
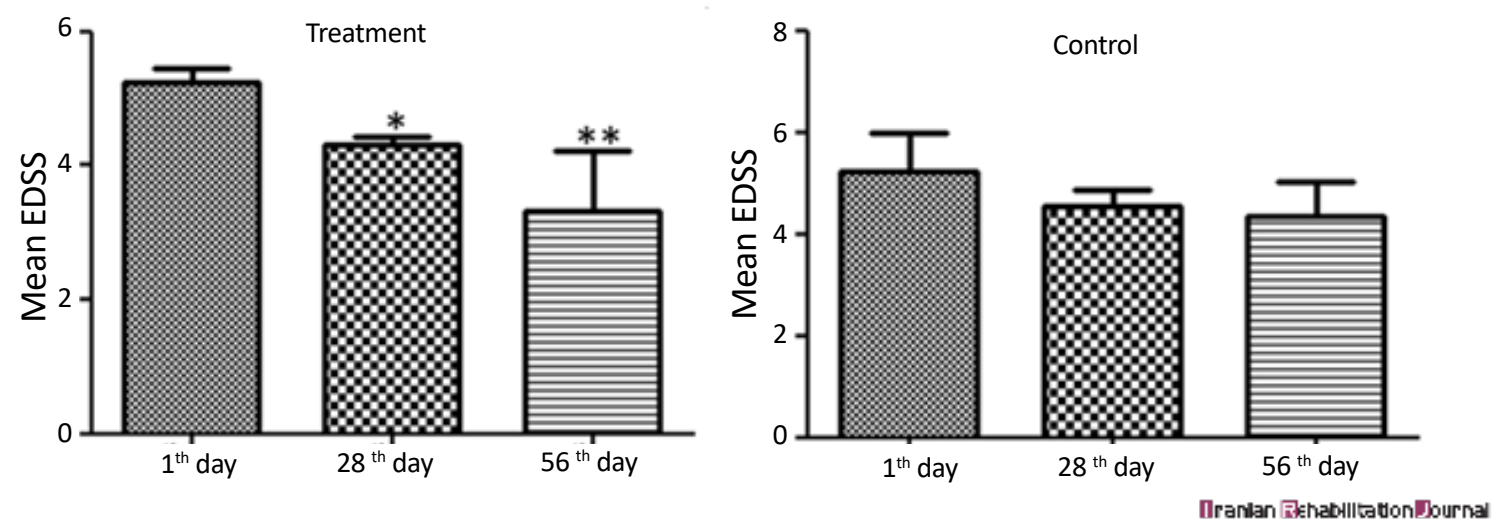

Figure 3. Expanded Disability Status Scale (EDSS), comparison on days 1, 28, and 56 post intervention in treatment and control groups.

${ }^{*} \mathrm{P}<0.01,{ }^{* *} \mathrm{P}<0.001$, compared with day 1 (Repeated measures test) 
Table 1. Demographic information of participants

\begin{tabular}{|c|c|c|c|c|c|c|}
\hline \multirow[t]{2}{*}{ Patients Demographic } & \multirow{2}{*}{$\begin{array}{c}\text { Variable } \\
20-30\end{array}$} & \multicolumn{2}{|c|}{$\begin{array}{l}\text { Treatment Group } \\
\text { Frequency (\%) }\end{array}$} & \multicolumn{2}{|c|}{$\begin{array}{l}\text { Control Group } \\
\text { Frequency (\%) }\end{array}$} & \multirow[t]{2}{*}{$\mathbf{P}$} \\
\hline & & 9 & 30 & 10 & 33.3 & \\
\hline \multirow[t]{2}{*}{ Age (year) } & $30-40$ & 16 & 53.3 & 14 & 46.6 & \multirow[t]{2}{*}{0.812} \\
\hline & Above 40 & 5 & 16.6 & 6 & 20 & \\
\hline \multirow{2}{*}{ Sex } & Female & 24 & 80 & 22 & 73.3 & \multirow{2}{*}{0.256} \\
\hline & Male & 6 & 20 & 8 & 26.7 & \\
\hline \multirow{3}{*}{ Marital status } & Single & 6 & 20 & 5 & 16.6 & \multirow{3}{*}{0.577} \\
\hline & Married & 23 & 76.6 & 23 & 76.6 & \\
\hline & Widow & 1 & 3.4 & 2 & 6.8 & \\
\hline \multirow{3}{*}{ Education } & Junior & 6 & 20 & 8 & 26.6 & \multirow{3}{*}{0.318} \\
\hline & High school & 18 & 60 & 14 & 46.6 & \\
\hline & College & 6 & 20 & 8 & 26.6 & \\
\hline \multirow{5}{*}{ Job } & Unemployed & 9 & 30 & 10 & 33.3 & \multirow{5}{*}{0.232} \\
\hline & Housewife & 12 & 40 & 13 & 43.3 & \\
\hline & Self-employed & 5 & 16.6 & 4 & 13.3 & \\
\hline & Employed & 1 & 3.3 & 2 & 6.6 & \\
\hline & Student & 3 & 10 & 1 & 3.3 & \\
\hline \multirow{3}{*}{ History of disease (year) } & 2 & 7 & 23.3 & 6 & 20 & \multirow{3}{*}{0.756} \\
\hline & $2-5$ & 11 & 36.6 & 10 & 13.3 & \\
\hline & Above 5 & 12 & 40 & 14 & 46.6 & \\
\hline \multirow{4}{*}{ Drugs } & Cinnovex & 15 & 50 & 13 & 43.3 & \multirow{4}{*}{0.517} \\
\hline & Recigen & 6 & 20 & 7 & 22.3 & \\
\hline & Avonex & 2 & 6.6 & 3 & 10 & \\
\hline & Rebif & 7 & 23.3 & 7 & 23.3 & \\
\hline
\end{tabular}

*T-test showed no significant difference in mean demographic data between the two groups.

Iranlan Rehabulltuton Journal

\section{Discussion}

Exercise therapy is a useful way to maintain the activities of daily living, cardiorespiratory health, muscular strength, and endurance in patients with MS [11]. Results of the present randomized clinical trials study confirm that isometric exercise has a significant impact on improving balance status and reduce disability in MS patients. Imbalance is one of the prevalent problems that could pose numerous risks to these patients [15]. Isometric exercise has the capability to apply a large contraction of specific group muscles, it could preserve motor output
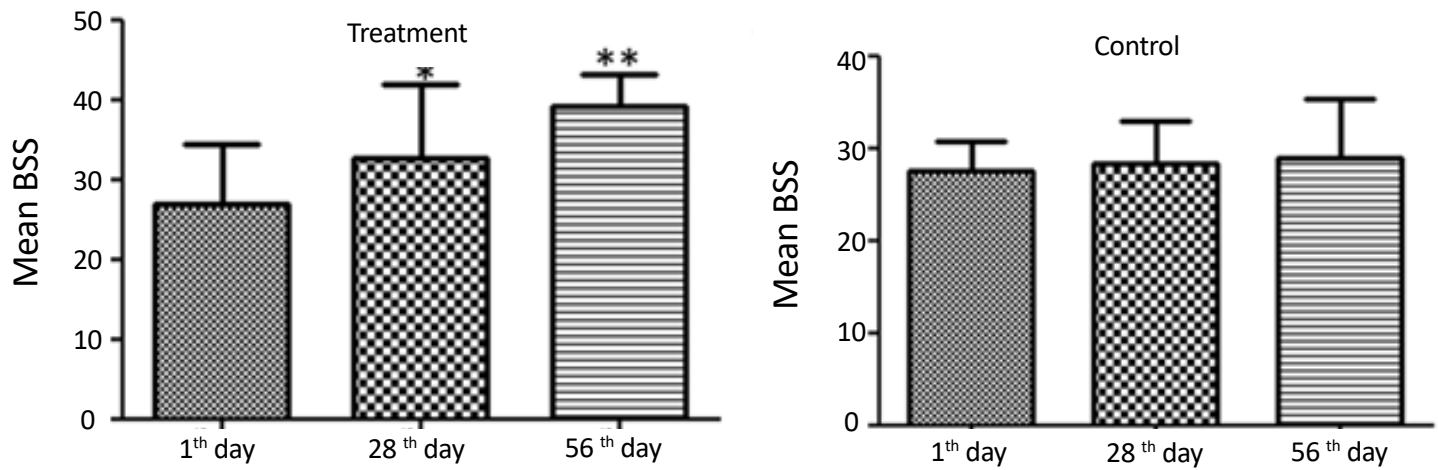

Figure 4. Berg Balance Scale (BBS), comparison at days 1, 28, and 56 post intervention in treatment and control groups

${ }^{*} \mathrm{P}<0.01,{ }^{* *} \mathrm{P}<0.001$, compared with day 1 (Repeated measures test) 
and is beneficial in preserving activities of daily living for MS patients [16]. As previously described, resistance exercise for 6 weeks has a beneficial effect on muscular strength and endurance in MS patients with wide range of disability [17]. In the present study, the balance improved $12 \%$ in the treatment group, whereas that in control group it was $2 \%$ on day 56 post intervention. Consistent with these results, Hoang et al demonstrated home exercise programs could improve balance, walking, and cognitive function in patients with MS [18].

Yoga training and postural equilibrium have been suggested to be effective for MS patients in maintaining the daily task and quality of life [19]. Furthermore, group exercise training has a beneficial effect on improvement of the balance, quality of life, and preservation of functional status [20]. Resistance training program on patients with MS demonstrated that these exercises improved muscle strength, balance, seated rowing, and leg extension on the treatment group [12].

Home exercise for MS patients is a practical and costeffective method and is efficient than formal exercise setting. However, there is a lack of precise control on sports activities of patients [21]. The same study demonstrated the home-based resistance exercise on balance could provide an efficient method and a viable solution for MS patients who prefer to exercise at home at reasonable cost [22]. We observed a significant improvement in the mean EDSS score of 1.94 on day 56 post intervention in the treatment group, whereas that in control group the mean EDSS score was found to be 0.52. Exercise therapy has several beneficial effects in MS patients; it could reduce the fatigue, stress, and could improve the balance and ambulatory function [23, 24].

Aerobic exercise was shown to have positive impacts on balance, walking, and cognitive function in MS patients, although it did not reach statistical significance on the mobility of lower extremity in patients with MS $[25,26]$. In another randomized controlled trail study, isometric training for 12 weeks enhanced muscle power and functional ability of patients with moderate MS [24]. One limitation of our study was the lack of detailed record of training of the patients because they were instructed to do the exercises at home and the assessment was based on self-report. We tried to overcome this shortcoming by repeated contacts with the patients and use of checklist that patients should mark at the end of each sport. MS is a neurological disease that affects physical activity by muscular weakness, stiffness, and spasticity. So far, it is difficult to introduce a definitive medication or a particular exercise for comprehensive treatment of the patients. Multimodal therapy is more beneficial to improve the postural problem, balance, and quality of life of patients with MS.

\section{Conclusion}

Present study demonstrated that isometric exercise for 8 weeks has the potential to improve balance and reduce disability in MS patients. However, long-term followup and further study is needed to determine the optimal duration and types of exercises that could enhance the functional capacity, cardiovascular endurance, balance, and muscle strength of MS patients.

\section{Acknowledgements}

Funding for this project was provided by Yasuj University of Medical Sciences, Iran.

\section{Conflict of Interest}

The authors declare no conflict of interests.

\section{References}

[1] Nazari F, Soheili M, Shaygannejad V, Valiani M. A comparison the effects of reflexology and relaxation on the psychological symptoms in women with multiple sclerosis. Journal of Education and Health Promotion. Medknow. 2017; 6(1):11. doi: 10.4103/jehp.jehp_166_14

[2] Roozbehi A, Joghataei MT, Bakhtiyari M, Mohammadi J, Rad P, Delaviz H. Age-associated changes on axonal regeneration and functional outcome after spinal cord injury in rats. Acta Medica Iranica. 2015. 53(5):281-6. PMID: 26024702

[3] Ghasemi N, Razavi S, Nikzad E. Multiple Sclerosis: Pathogenesis, Symptoms, Diagnoses and Cell-Based Therapy. Cell. 2017. 19(1):1-10. PMCID: PMC5241505

[4] Anderson DW, Ellenberg JH, Leventhal CM, Reingold SC, Rodriguez M, Silberberg DH. Revised estimate of the prevalence of multiple sclerosis in the united states. Annals of Neurology. 1992; 31(3):333-6. doi: 10.1002/ana.410310317

[5] Shaygannejad V, Ardestani PE, Ghasemi M, Meamar R Restless legs syndrome in Iranian multiple sclerosis patients: a case-control study. International Journal of Preventive Medicine. 2013; 4(Suppl 2):S189-93.

[6] Sangelaji B, Estebsari F, Nabavi SM, Jamshidi E, Morsali D, Dastoorpoor M. The effect of exercise therapy on cognitive functions in multiple sclerosis patients: A pilot study. Medical Journal of the Islamic Republic of Iran. 2015. 29:205. PMCID: PMC4476225

[7] Peiravian F, Rajaian H, Samiei A, Gholijani N, GharesiFard B, Mokaram P, et al. Altered Serum Cytokine Profiles 
in Relapse Phase of Relapsing-Remitting Multiple Sclerosis. Iranian Journal of Immunology. 2016. 13(3):186-96. PMID: 27671510

[8] Yang H, Duchesneau E, Foster R, Guerin A, Ma E, Thomas NP. Cost-effectiveness analysis of ocrelizumab versus subcutaneous interferon beta-1a for the treatment of relapsing multiple sclerosis. Journal of Medical Economics. 2017; 20(10):1056-65. doi: 10.1080/13696998.2017.1355310

[9] Roozbehi A, Joghataie MT, Mehdizadeh M, Mirzaei A, Delaviz $\mathrm{H}$. The effects of cyclosporin-A on functional outcome and axonal regrowth following spinal cord injury in adult rats. Acta Medica Iranica. 2012; 50(4):226-32.

[10] Delaviz H, Joghataie MT, Mehdizadeh M, Bakhtiyari M, Nobakht M, Khoei S. Transplantation of olfactory mucosa improve functional recovery and axonal regeneration following sciatic nerve repair in rats. Iranian Biomedical Journal. 2008; 12(4):197-202. PMID: 19079532

[11] Sangelaji B, Kordi MR, Banihashemi F, Nabavi SM, Khodadadeh S, Dastoorpoor M. A combined exercise model for improving muscle strength, balance, walking distance, and motor agility in multiple sclerosis patients: A randomized clinical trial. Iranian Journal of Neurology. 2016. 15(3):111-20. PMCID: PMC5027145

[12] Moradi M, Sahraian MA, Aghsaie A, Kordi MR, Meysamie A, Abolhasani M. Effects of Eight-week Resistance Training Program in Men With Multiple Sclerosis. Asian Journal of Sports Medicine. 2015; 6(2). doi: 10.5812/asjsm.6(2)2015.22838

[13] Thompson AJ, Hobart JC. Multiple sclerosis: assessment of disability and disability scales. Journal of Neurology. 1998; 245(4):189-96. doi: 10.1007/s004150050204

[14] Karpatkin HI, Cohen ET, Klein S, Park D, Wright C, Zervas $M$. The Effect of Maximal Strength Training on Strength, Walking, and Balance in People with Multiple Sclerosis: A Pilot Study. Multiple Sclerosis International. 2016; 2016:1-6. doi: $10.1155 / 2016 / 5235971$

[15] Petracca M, Saiote C, Bender HA, Arias F, Farrell C, Magioncalda $\mathrm{P}$, et al. Synchronization and variability imbalance underlie cognitive impairment in primary-progressive multiple sclerosis. Scientific Reports. Springer Nature; 2017; 7:46411. doi: 10.1038/srep46411

[16] Pepin EB, Hicks RW, Spencer MK, Tran ZV, Jackson CGR. Pressor response to isometric exercise in patients with multiple sclerosis. Medicine \& Science in Sports \& Exercise 1996; 28(6):656-60. doi: 10.1097/00005768-199606000-00002

[17] Svensson B, Gerdle B, Elert J. Endurance Training in Patients With Multiple Sclerosis: Five Case Studies. Physical Therapy. 1994; 74(11):1017-26. doi: 10.1093/ptj/74.11.1017

[18] Hoang P, Schoene D, Gandevia S, Smith S, Lord SR. Effects of a home-based step training programme on balance, stepping, cognition and functional performance in people with multiple sclerosis - a randomized controlled trial. Multiple Sclerosis Journal. 2015; 22(1):94-103. doi: $10.1177 / 1352458515579442$

[19] Najafi P, Moghadasi M. The effect of yoga training on enhancement of Adrenocorticotropic hormone (ACTH) and cortisol levels in female patients with multiple sclerosis. Complementary Therapies in Clinical Practice. 2017; 26:21-25. doi 10.1016/j.ctcp.2016.11.006. doi: 10.1016/j.ctcp.2016.11.006
[20] Tarakci E, Yeldan I, Huseyinsinoglu BE, Zenginler Y, Eraksoy M. Group exercise training for balance, functional status, spasticity, fatigue and quality of life in multiple sclerosis: A randomized controlled trial. Clinical Rehabilitation. 2013; 27(9):813-22. doi: 10.1177/0269215513481047

[21] Ortiz-Rubio A, Cabrera-Martos I, Rodríguez-Torres J, Fajardo-Contreras W, Díaz-Pelegrina A, Valenza MC. Effects of a Home-Based Upper Limb Training Program in Patients With Multiple Sclerosis: A Randomized Controlled Trial. Archives of Physical Medicine and Rehabilitation. 2016; 97(12):2027-33. doi: 10.1016/j.apmr.2016.05.018

[22] Griffith G, Klaren RE, Motl RW, Baynard T, Fernhall B. Experimental protocol of a randomized controlled clinical trial investigating exercise, subclinical atherosclerosis, and walking mobility in persons with multiple sclerosis. Contemporary Clinical Trials. 2015; 41:280-6. doi: 10.1016/j.cct.2015.02.003

[23] DeBolt LS, McCubbin JA. The effects of home-based resistance exercise on balance, power, and mobility in adults with multiple sclerosis. Archives of Physical Medicine and Rehabilitation. 2004; 85(2):290-7. doi: 10.1016/j.apmr.2003.06.003

[24] Dalgas U, Stenager E, Jakobsen J, Petersen T, Hansen $\mathrm{HJ}$, Knudsen C, et al. Resistance training improves muscle strength and functional capacity in multiple sclerosis. Neurology. 2009; 73(18):1478-84. doi:10.1212/wnl.0b013e3181bf98b4

[25] Kara B, Küçük F, Poyraz E coşkuner, Tomruk MS, İdıman E. Different types of exercise in Multiple Sclerosis: Aerobic exercise or Pilates, a single-blind clinical study. Journal of Back and Musculoskeletal Rehabilitation. 2017; 30(3):565-73. doi: 10.3233/bmr-150515

[26] Medina-Perez C, de Souza-Teixeira F, Fernandez-Gonzalo R, Hernandez-Murua JA, Antonio de Paz-Fernandez J. Effects of high-speed power training on muscle strength and power in patients with multiple sclerosis. Journal of Rehabilitation Research and Development. Journal of Rehabilitation Research \& Development; 2016; 53(3):359-68. doi: 10.1682/ jrrd.2014.08.0186 